\title{
Research Paper: Determinants of Completing the Medication Reconciliation Form Among Nurses Based on Diffusion of Innovation Theory
}

\author{
Sara Heydari' ${ }^{1}$, Mojtaba Fattahi Ardakani ${ }^{*}$ D, Elham Jamei², Soheila Salahshur ${ }^{2}$
}

1. Department of Medical Education, Medical Education Research Center, Isfahan University of Medical Sciences, Iran.

2. Department of Health Education, School of Public Health, Shahid Sadoughi University of Medical Sciences, Yazd, Iran.

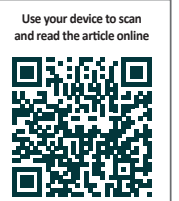

Citation Heydari S, Fattahi Ardakani M, Jamei E, Salahshur S. Determinants of Completing the Medication Reconciliation Form Among Nurses Based on Diffusion of Innovation Theory. Journal of Research \& Health. 2020; 10(3):151-158. http:// dx.doi.org/10.32598/JRH.10.3.1491.1

doif: http://dx.doi.org/10.32598/JRH.10.3.1491.1

\section{(i) (5)}

Article info:

Received: 13 Jan 2018

Accepted: 23 May 2018

Publish: 01 May 2020

\section{Keywords:}

Innovation diffusion, Management, Medication reconciliations, Nurse, Patient safety

\begin{abstract}
Background: Patients afety is a global medical concern with remarkable influence on the health of patients. Studies have suggested that treatment-related damages occur in approximately $10 \%$ of patients at variable degrees, and more than a quarter of these damages are associated with medication errors. Medication errors could be diminished during patient hospitalization and transferusing integrated medication reconciliation. This study aimed to evaluate the determinants of completing integrated medication reconciliation forms based on the theory of diffusion of innovations among the nurses of Ziaei Hospital of Ardakan City and Imam Jafar Sadegh Hospital of Meybod City, Yazd.
\end{abstract}

Materials and Methods: In this study, required data were collected from the nurses engaged in the admission centers of the selected hospitals using researcher-made questionnaires. Data analysis was performed in SPSS v. 19 using Spearman's correlation-coefficient and MannWhitney U test.

Results: Findings of this study regarding different structures of integrated medication reconciliation forms were as follows: relative advantage (86.5 of the maximum score), perceived compatibility (40.75), perceived complexity (44.3), visibility (83.6), and testability (79.8). Moreover, significant correlations were observed between the structures of comparative advantage, perceived compatibility, testability, and visibility.

Conclusion: According to the results of this study, promoting the knowledge and professional attitude of nurses could increase their compatibility regarding the implementation of integrated medication reconciliation. In addition, elaboration on the proper principles of the completion of this form could reduce the mean score of the perceived complexity structure.

\section{* Corresponding Author:}

Mojtaba Fattahi Ardakani, PhD.

Address: Department of Medical Education, Medical Education Research Center, Isfahan University of Medical Sciences, Iran.

Phone: +98 (913) 3566877

E-mail:mifattahi57@gmail.com 


\section{Introduction}

atient safety is a global medical concern in all areas of healthcare services $\mathbf{P}$ in developed and developing countries. Statistically, it has been found that treatment-borne damages occur in approximately $10 \%$ of all hospitalized patients at variable degrees [1].

Based on studies conducted in Australia, $16.6 \%$ of hospitalized patients experience adverse events, which may lead to temporary disabilities (77\%), permanent disabilities $(15 \%)$, and death $(5 \%)[2]$.

Recent reports have confirmed that medication errors account for more than a quarter of problems affecting patients during hospitalization and treatment [3, 4]. Medication errors mostly occur during the processes of preparation, prescription, distribution, and monitoring of therapeutic drugs. Time of admission has been recently proposed as a significant factor in the occurrence of treatment-related complications. More than $50 \%$ of patients had been subjected to medication errors at the time of admission due to errors in their medical history [5].

Medication errors can lead to several problems, including high hospitalization costs, increased mortality rate, and lack of patients' trust and satisfaction with hospital services [6]. In Iran, the Ministry of Health and Education allocates billions of dollars every year to compensate for the cost of medication and admission errors [7].

However, many medication errors are preventable and can be corrected with efficient management. Base on a study, $48 \%$ of these errors are preventable [1]. According to the results of another study, two-thirds of patients' complications upon admission were reported to be preventable with efficient management [8]. Incompatibility in prescribed drugs after discharge plays a critical role in the occurrence of adverse medical events. Discharged patients are at a higher risk of complications caused by medication incompatibility as they return to normal social life $[9,10]$. In this regard, the findings of Forrester indicate that $23 \%$ of the patients discharged from a teaching hospital in Canada experienced unwanted side effects, $72 \%$ of which were associated with drug administration [11].

Medication reconciliation is an effective strategy to reduce medication errors and several studies have proved its effectiveness [12]. For instance, the results of a report confirmed that integrated medication reconciliation could reduce medical errors by $70 \%$ within 7 months [13]. Medication reconciliation is mainly based on providing a complete medical history, which differs from the routine medical record of the patient [1]. The required medical history is provided through a systematic process of interviewing the patient and referring to credible sources (e.g., pharmacies and physicians) [14]. However, since the patient's interview may be time-consuming, healthcare providers tend to neglect this process, which exposes patients to a higher risk of unexpected medication and treatment-related errors [15]. Furthermore, integrated medication reconciliation is widely used for patients who are unfamiliar with prescription medications.

Diffusion of innovations is a theory of the main principles used to facilitate the adaption of healthcare providers with a specific procedure. The proper implementation of this theory requires a suitable setting and the aspect of innovation highlights the ideas, issues, and functions that are considered unprecedented by another individual. In this context, the term "unprecedented" refers to the situation in which a potential recipient has had no previous contact with the other applications of a certain new product or idea [16].

In applying the diffusion of innovations theory, health authorities are faced with unestablished interventions and their impact on a certain process [17]. For a new approach to become established and widely practiced, three main components are required: the new idea must be accepted by influential people, the new idea must be of great quality or with notable characteristics to encourage people to follow the idea, and the new idea must have remarkable environmental and social impacts [18].

In a study, Forster et al. measured the acceptance rate of preventive pharmaceutical procedures in a medical high school in 2002. According to the findings, the two structures of relative advantage and perceived compatibility were most effective in the adaption of new processes [19].

In this regard, another research was conducted by $\mathrm{McGa}$ et al. to evaluate the role of a multi-team approach in patient transfer in 2007, emphasizing the safety of patients. According to the findings, more than $90 \%$ of discharged patients had at least one potential exposure to medication side effects. In their study, adequate training of nurses and improvement of nursing skills in medication assessment reduced the risk of mortality by at least $78 \%$. Furthermore, less than $28 \%$ of the patients required follow-up and revisits which ultimately reduced treatment costs [20]. 
Considering the importance of medication reconciliation and the creation of an appropriate framework for the proper acceptance of this process, the researchers tried to investigate the determinants of using medication reconciliation in nurses based on diffusion of innovation theory.

\section{Methods}

This cross-sectional study was conducted on 91 nurses engaged in intensive care units, internal medicine departments, surgery wards, cardiac care units, gynecology, and pediatric wards in two general hospitals in Ardakan and Meybod Cities of Yazd Province, in May 2016. The participants completed a researcher-made questionnaire designed based on the diffusion of innovations theory. The validity of the questionnaire was reviewed by a panel of experts and its content validity ratio and content validity index were examined and approved. To remove any ambiguity in understanding each item, the questionnaire was sent to 10 nurses and their comments were taken. The reliability of the questionnaire was also evaluated by conducting a pilot study on 15 nurses who were later excluded from the study. The final questionnaire included the following subscales:

1. Relative advantage: This construct contains 6 items and the acquired score ranges from 6 to 35. In this construct, the positive results of the reconciliation form are questioned. Its reliability is 0.87 calculated by the Cronbach $\alpha$ coefficient.

2: Perceived compatibility: This construct includes 4 items to measure the compatibility of integrated medication with professional requirements $(\alpha=0.59)$.

3. Visibility: It includes two items scoring based on a 5-point Likert scale from completely correct to completely wrong. The possible scores ranged from 2-10 $(\alpha=0.74)$

4. Testability: This construct is measured with 2 items based on a 5-point Likert scale. The possible score for the construct ranged from $2-10(\alpha=0.62)$.

5. Perceived complexity: In this structure, 4 items are scored inversely. If the completion or learning of the form is considered hard, it will gain lower scores. The acquired score ranged from 4-20 $(\alpha=0.56)$. Subjective norms (with six items) $(\alpha=0.75)$ and intention (with three items) $(\alpha=0.65)$ are the other constructs.
The collected data were entered into SPSS v.13. Onesample Kolmogorov-Smirnov test showed that the data were non-normally distributed. Thus, the Spearman rank correlation coefficient was used to determine the correlation between variables and the Mann-Whitney U test was used to compare the groups (significance level at $<0.05$ )

\section{Results}

In total, 91 nurses were enrolled in this study, selected via census sampling. They were assured of the confidentiality of the information, and then the questionnaires were provided to them to complete.

The participants' Mean \pm SD of age was $34.36 \pm 7.25$ years. In terms of educational status, 10 participants had a diploma in paramedical sciences and 57 nurses a $\mathrm{BA}$ in nursing. Their Mean $\pm \mathrm{SD}$ clinical experience was $10 \pm 8.15$ years (range: $1-26$ years). Besides, 30 participants were male $(33.3 \%)$ and 60 were female $(65.9 \%)$.

According to Table 1, 40\% of the nurses found it difficult to complete integrated medication reconciliation forms, and $80 \%$ did not consider this healthcare strategy to be in line with clinical professional values. Moreover $78 \%$ of the participants were concerned that the implementation of the integrated medication program might interfere with their working time frame.

Concerning the structure of relative advantage, the majority of the nurses agreed with the benefits of the integrated medication reconciliation. As such, $82 \%$ of nurses believed that the use of this healthcare strategy contributed to effective patient management.

As revealed in Table 2, two structures of perceived complexity (44.3\%) and relative advantage (40.75\%) received the lowest scores obtained by the participants, while the structures, intention $(91.83 \%)$ and relative advantage $(86.5 \%)$ had the highest scores obtained by the participants.

The mean score of relative advantage was higher among male participants, and there was a significan difference in this regard $(\mathrm{P}=0.034)$. Furthermore, the mean scores of the structures, perceived complexity $(\mathrm{P}=0.001)$, and intention $(\mathrm{P}=0.013)$ were higher among male participants, and significant differences were observed in this regard.

Table 3 indicates a direct correlation between the structures of perceived relative advantage and intention to 
Table 1. Distribution of responses to items of relative advantage, perceived compatibility, and perceived complexity

\begin{tabular}{|c|c|c|c|c|c|c|}
\hline & \multirow[b]{2}{*}{ Items } & \multicolumn{5}{|c|}{ No. (\%) } \\
\hline & & $\begin{array}{l}\text { Totally } \\
\text { Agree }\end{array}$ & Agree & $\begin{array}{l}\text { Do Not } \\
\text { Know }\end{array}$ & Disagree & $\begin{array}{l}\text { Totally } \\
\text { Disagree }\end{array}$ \\
\hline \multirow{3}{*}{$\begin{array}{l}\text { Perceived } \\
\text { complexity }\end{array}$} & $\begin{array}{l}\text { Learning to complete integrated medi- } \\
\text { cation reconciliation forms is difficult } \\
\text { for nurses. }\end{array}$ & 9 (9.9) & 29 (31.9) & $30(33)$ & $20(22.0)$ & $3(3.2)$ \\
\hline & $\begin{array}{l}\text { The use of integrated medication rec- } \\
\text { onciliation forms }\end{array}$ & $10(11)$ & $18(19.8)$ & 36 (39.6) & $22(24.2)$ & $5(5.4)$ \\
\hline & $\begin{array}{l}\text { It is quite easy to complete integrated } \\
\text { medication reconciliation forms even } \\
\text { for nurses who attempt to do it for the } \\
\text { first time. }\end{array}$ & $5(5.5)$ & $33(36.3)$ & $29(31.8)$ & $20(22)$ & $4(4.4)$ \\
\hline \multirow{3}{*}{$\begin{array}{l}\text { Perceived } \\
\text { compatibility }\end{array}$} & $\begin{array}{l}\text { It is my professional duty to implement } \\
\text { integrated medication reconciliation. }\end{array}$ & $27(29.7)$ & $40(44)$ & $17(18.7)$ & $4(4.4)$ & $3(3.2)$ \\
\hline & $\begin{array}{l}\text { Nurses are concerned whether the use } \\
\text { of integrated medication reconciliation } \\
\text { interferes with their working time. }\end{array}$ & 1 (1.1) & $5(5.5)$ & $14(15.3)$ & 45 (49.5) & $26(28.6)$ \\
\hline & $\begin{array}{l}\text { Integrated medication reconciliation is } \\
\text { in line with professional values. }\end{array}$ & 1 (1.1) & $3(3.3)$ & $16(17.5)$ & 41 (45.1) & $30(33)$ \\
\hline \multirow{3}{*}{$\begin{array}{l}\text { Relative advan- } \\
\text { tage }\end{array}$} & $\begin{array}{l}\text { The implementation of integrated } \\
\text { medication determines the list of } \\
\text { required drugs for patients. }\end{array}$ & 41 (45.1) & $43(47.3)$ & $4(4.4)$ & $2(2.2)$ & $1(1.1)$ \\
\hline & $\begin{array}{l}\text { The implementation of integrated } \\
\text { medication reconciliation prevents the } \\
\text { misuse or excessive consumption of } \\
\text { previous drugs by the patient. }\end{array}$ & $42(46.2)$ & 36 (39.6) & $8(8.8)$ & $4(4.3)$ & $1(1.1)$ \\
\hline & $\begin{array}{l}\text { The proper use of integrated medica- } \\
\text { tion reconciliation contributes to effec- } \\
\text { tive patient management. }\end{array}$ & $39(42.8)$ & $40(44)$ & $9(9.9)$ & $2(2.2)$ & $1(1.1)$ \\
\hline
\end{tabular}

complete the integrated medication reconciliation forms. Therefore, a higher mean score of relative advantage resulted in the increased mean score of the intention structure; however, this correlation was not significant. Moreover, the correlations between the constructs of testability and visibility were not statistically significant.

\section{Discussion}

In the present study, the mean scores of different structures of diffusion of innovations theory were evaluated among the nursing staff of two public hospitals. According to the findings, the highest scores belonged to the structures of perceived relative advantage, testability, and visibility, while the lowest scores belonged to the structures of perceived compatibility and complexity. Therefore, the majority of nurses believed that the com- pletion of integrated medication reconciliation forms is difficult or interferes with their professional values and working timeframe.

As shown in Table 1, 40\% of the nurses found it difficult to complete the forms of integrated medication reconciliation; $80 \%$ did not believe this strategy to be in line with professional values, and nearly $78 \%$ were concerned that this program might interfere with their working time frame. Furthermore, the results of the present study indicated that the structures of relative advantage, perceived compatibility, and perceived complexity of social networks were positively correlated with the tendency of nursing staff toward using these networks. In other studies, the lack of dissemination and acceptance of the innovation has been due to the complexity of health systems [21, 22]. 
Table 2. The tendency of nursing staff towards the completion of integrated medication reconciliation forms based on gender in the model of diffusion of innovations

\begin{tabular}{cccccc}
\hline \multirow{2}{*}{ Construct } & \multicolumn{3}{c}{ Mean \pm SD } & Total Score & Sig. \\
\cline { 2 - 5 } & Male & Female & Total & & (\%) \\
\hline Relative advantage & $27.2 \pm 2.74$ & $4.07 \pm 25.36$ & $3.75 \pm 25.95$ & 86.5 & 0.034 \\
\hline Perceived compatibility & $2.15 \pm 8.40$ & $1.85 \pm 8.06$ & $1.96 \pm 8.15$ & 40.75 & 0.621 \\
\hline Perceived complexity & $1.83 \pm 9.60$ & $1.99 \pm 8.50$ & $1.99 \pm 8.86$ & 44.3 & 0.010 \\
\hline Testability & $1.28 \pm 7.83$ & $5.36 \pm 8.06$ & $4.42 \pm 7.98$ & 79.8 & 0.332 \\
\hline Visibility & $1.14 \pm 8.70$ & $1.22 \pm 8.16$ & $1.22 \pm 8.36$ & 83.6 & 0.060 \\
\hline Subjective Norm & $3.91 \pm 24.13$ & $7.69 \pm 23.63$ & $6.62 \pm 23.80$ & 79.33 & 0.301 \\
\hline Intention & $2.25 \pm 11.86$ & $2.07 \pm 10.60$ & $2.19 \pm 11.02$ & 91.83 & 0.013 \\
\hline
\end{tabular}

URA

Table 3. Correlations between intention and the structures of the diffusion of innovations theory based on the Spearman correlation coefficient

\begin{tabular}{cccccc}
\hline Construct & Relative Advantage & Compatibility & Complexity & Testability & Visibility \\
\hline Intention & $0.325^{* *}$ & 0.171 & $0.231^{*}$ & $0.405^{* *}$ & $0.299^{* *}$ \\
$\mathrm{P}$ & 0.002 & 0.12 & 0.02 & $0.001>$ & $0.001>$ \\
\hline
\end{tabular}

${ }^{*} \mathrm{p}<0.1$

$* * \mathrm{P}<0.05$

The complexity of systems can be related to the structure, process, and patterns. For example, to change the method of drug delivery in a hospital, there needs to be a change in the real environment. In a system, individual factors, patterns of relationships, and beliefs should be considered. Overlooking these factors can cause more complexity of the system, as observed in the present study [21]. The findings of the current study confirmed the correlation between the tendency towards the application of the innovation theory and the use of social networks.

With respect to the relative advantage construct, $82.2 \%$ of the nurses believed that the implementation of integrated medication reconciliation contributed to effective patient management. In this regard, a study was conducted by Abdullah Al-Mubariz Saud et al. [23] in which the rate of the internet acceptance was measured based on Roger's diffusion of innovations theory, and recipients were categorized into innovators, early majority, late majority, delayed recipients, and survivors. According to the results of multiple regression analysis, the researchers concluded that the innovation structures, including relative advantage, perceived complexity, testability, perceived compatibility, and visibility were effective in the acceptance of the internet by the participants. Furthermore, they reported that the structure of relative advantage had the most significant effect on the rate of internet acceptance compared to the other aspects of innovation. In the present study, the relative advantage structure was positively correlated with the intention of nursing personnel to complete integrated medication reconciliation forms [24].

Compatibility is another key element of innovation diffusion, which can influence the reception and the use of innovation. In the current study, the majority of the nurses were concerned that the implementation of integrated medication reconciliation might interfere with their working time frame, suggesting that this healthcare strategy has not been considered by nursing personnel. Therefore, nurses should be assured that the implementation of this program helps with their professional values. This finding was consistent with the results obtained by Forster et al. that evaluated the attitude towards preventive procedures in a medical high school in 2002 [19]. According to their findings, the two structures of relative advantage and perceived compatibility were essentially 
correlated with the tendency of healthcare staff towards the use of new pharmaceutical approaches [19].

Vedela et al. study results indicate that in individuals with a lower perception of the complexity of clinical systems, there is a direct correlation between comprehended simplicity and reduced perceived complexity [25]. Moreover, the perception of the functionality of the system is correlated with the relative advantage structure, and concerns regarding the patient-physician relationship are associated with the compatibility of the system. Accordingly, the higher perception of the functionality of the system is correlated with the structure of relative advantage [26].

The findings of the current study indicate a direct correlation between the structures of testability and visibility and the structure of tendency to complete the forms of integrated medication reconciliation among nurses. This finding was in line with the results obtained by Khalesi et al. assessing the users of hospital information systems [27]. Furthermore, the authors stated that visibility had a significant effect on the tendency of hospital staff towards the use of information systems. In this regard, the findings of Pankratz et al. revealed that in the proposed diffusion of innovations theory, innovation structures (visibility, perceived compatibility, professional relations, and internal and external environment) were significant predictors of the attitude of healthcare professionals towards the use of smartphones [28].

In other related studies, factors such as the reception of consumption management systems, human and ergonomics factors in the hospital, and different structures of innovation in rehabilitation management had significant associations with relative advantage, perceived compatibility, and perceived complexity. These findings are consistent with the results of the present study [29, 30].

Therefore, it is suggested that the modified version of the diffusion of innovations theory is adopted as a proper measure for clinical data collection to predict and comprehend the use of social networks.

\section{Conclusion}

The results of the current study indicated that acceptance of innovation in the completion of integrated medication reconciliation forms requires the increasing of nursing staff knowledge, as well as the reduction of the complexity of this strategy to help with the nursing profession. The researcher pointed out that the study lacked any impact on the performance of the personnel and their perception could affect the process of completing the questionnaire.

\section{Ethical Considerations}

\section{Compliance with ethical guidelines}

This study is a part of a protocol approved by the Ethics Committee of Shahid Sadoughi University of Medical Sciences, Yazd, Iran (Code: IRSSU.SPH.REC.1395.76).

Funding

This research did not receive any specific grant from funding agencies in the public, commercial, or non-profit sectors.

\section{Authors' contributions}

Conceptualization and Writing - Original Draft: Mojtaba Fattahi Ardakani; Methodology and Writing Review \& Editing: Sara Heydari sharifabad, Mojtaba Fattahi Ardakani; Investigation: all author; Funding Acquisition and Supervision: Sara Heydari sharifabad.

\section{Conflict of interest}

The authors declared no conflict of interest.

\section{Acknowledgments}

The authors appreciate the people who participated in this work, including the managers and nurses of Imam Jafar Sadegh Hospital of Meybod and Ziaee Hospital of Ardakan.

\section{Refrences}

[1] Brennan TA, Leape LL, Laird NM, Hebert L, Localio AR, Lawthers AG, et al. Incidence of adverse events and negligence in hospitalized patients: Results of the Harvard Medical Practice Study I. N Engl J Med. 1991; 324(6):370-6. [DOI:10.1056/NEJM199102073240604] [PMID]

[2] Kohn LT, Corrigan JM, Donaldson MS. To err is human: Building a safer health system. Washington: National Academies Press; 2000. https://books.google.com/ books?id=8r1QAQAAIAAJ\&q

[3] Wachter R. Understanding patient safety. New York: McGraw Hill Professional; 2012. https:/ / books.google.com/ books?id=9BuLAwAAQBAJ\&dq

[4] Baker GR, Norton PG, Flintoft V, Blais R, Brown A, Cox J, et al. The Canadian adverse events study: The incidence of 
adverse events among hospital patients in Canada. CMAJ. 2004; 170(11):1678-86. [DOI:10.1503/cmaj.1040498] [PMID] [PMCID]

[5] Wilson RM, Runciman WB, Gibberd RW, Harrison BT, Newby L, Hamilton JD. The quality in Australian health care study. Med J Aust. 1995; 163(9):458-71. [DOI:10.5694/j.1326-5377.1995.tb124691.x] [PMID]

[6] Vozikis A. Information management of medical errors in Greece: The MERIS proposal. Int J Inf Manage. 2009; 29(1):1526. [DOI:10.1016/j.ijinfomgt.2008.04.012]

[7] Moghaddasi H, Sheikhtaheri A, Hashemi N. [Reducing medication errors: Role of computerized physician order entry system (Persian)]. J Health Adm. 2007; 10(27):57-67. http:// jha.iums.ac.ir/browse.php?a_id=74\&sid=1\&slc_lang=en

[8] Akhlaghi M, Towfighi ZH, Samadi F. Analysis of medical malpractice complaints in gynecology and obstetric reffered to the medical commission of L.M.O in Tehran from 20012002: Causes \& preventative resolutions. Sci J Forensic Med. 2004; 10(34):4-70. https://www.sid.ir/en/Journal/ViewPaper.aspx?ID $=80357$

[9] Toufighi H, Shirzad J, Ghadipasha M. Assessment of medical negligence leading to death in legal medicine organization sessions between 1995 and 1999. Sci J Forensic Med. 2002; 8(27):5-8. https://www.sid.ir/en/journal/ViewPaper. aspx?id=74677

[10] Naghibi K, Montazari K, Khalifeh Soltani SS. [Investigation of medical complaint files in Medical Affairs Organization (Persian)]. J Isfahan Med Sch. 2011; 29(157):1542-53. http:// jims.mui.ac.ir/index.php/jims/article/view/1436

[11] Reason JT. Managing the risks of organizational accidents. Farnham: Ashgate; 1997. https://books.google.com/ books?id=ZnhRAAAAMAAJ\&q

[12] Pronovost P, Weast B, Schwarz M, Wyskiel RM, Prow D, Milanovich SN, et al. Medication reconciliation: A practical tool to reduce the risk of medication errors. J Crit Care. 2003; 18(4):201-5. [DOI:10.1016/j.jcrc.2003.10.001] [PMID]

[13] Leape LL, Brennan TA, Laird N, Lawthers AG, Localio AR, Barnes BA, et al. The nature of adverse events in hospitalized patients: Results of the Harvard Medical Practice Study II. N Engl J Med. 1991; 324(6):377-84. [DOI:10.1056/ NEJM199102073240605] [PMID]

[14] Tam VC, Knowles SR, Cornish PL, Fine N, Marchesano R, Etchells EE. Frequency, type and clinical importance of medication history errors at admission to hospital: A systematic review. CMAJ. 2005; 173(5):510-5. [DOI:10.1503/cmaj.045311] [PMID] [PMCID]

[15] Kohn LK, Corrigan JM, Donaldson MS. To Err Is Human: Building a safer health system. Committee on Quality of Health Care in America: Institute of Medicine. In: (US) IoM, editor. Washington: National Academy Press; 1999.

[16] Sanghera IS, Franklin BD, Dhillon S. The attitudes and beliefs of healthcare professionals on the causes and reporting of medication errors in a UK intensive care unit. J Anaesth Great Britain and Ireland. 2007; 62:53-61. [DOI:10.1111/j.13652044.2006.04858.x] [PMID]

[17] Abir O, Kanaan, Jennifer L, Donovan, Nerissa P, Duchin $\mathrm{B}$, et al. Adverse drug events after hospital discharge in older adults. J Am Geriatr Soc. 2013; 61(11):1894-9. [DOI:10.1111/ jgs.12504] [PMID] [PMCID]

[18] Winterstein AG, Sauer BC, Hepler CD, Poole C. Preventable drug-related hospital admissions. Ann Pharmacother. 2002; 36(7-8):1238-48. [DOI:10.1345/aph.1A225] [PMID]

[19] Forster AJ, Murff HJ, Peterson JF. The incidence and severity of adverse events affecting patients after discharge from the hospital. Ann Intern Med. 2003; 138:161-7. [DOI:10.7326/00034819-138-3-200302040-00007] [PMID]

[20] Rozich JD, Resar RK. Medication safety: One organization's approach to the challenge. J Clin Outcomes Manag. 2001; 8:27-34. https://scinapse.io/papers/2340290816

[21] Whittington J, Cohen H. OSF healthcare's journey in patient safety. Qual Manag Health Care. 2004; 13(1):53-9. [DOI:10.1097/00019514-200401000-00005] [PMID]

[22] Rozich JD, Howard RJ, Justeson JM, Macken PD, Lindsay ME, Resar RK. Standardization as a mechanism to improve safety in health care. Jt Comm J Qual Saf. 2004; 30(1):5-14. [DOI:10.1016/S1549-3741(04)30001-8]

[23] Almobarraz A. Perceived attributes of diffusion of innovationtheory as predictors of internet adoption among the faculty members of Imam Mohammed Bin Saud University [PhD dissertation]. Denton: University of North Texas; 2007. https:/ / digital.library.unt.edu/ark:/67531/metadc3710/)

[24] Institute for Healthcare Improvement Preventing adverse drug events through medication reconciliation. 2009 [Version current January 20, 2009]; Available from: http://www.ihi. org/IHI/Programs/AudioAndWebPrograms/WebandACTIONMedReconciliation.htm.

[25] Vedela I, Lapointe L, Lussierc MT, Richard C, Goudreauc J, Lalondec L, et al. Healthcare professionals' adoption and use of a clinical information system (CIS) in primary care: Insights from the Da Vinci study. Jt Comm J Qual Saf. 2012; 81(2):7387. [DOI:10.1016/j.ijmedinf.2011.11.002] [PMID]

[26] Safari M. Theories, models and methods of health education and health promotion. Tehran: Sobhan works; 2011.

[27] Khalesi N, Ahmadi M. A study on the attitudes of users about application of admission discharge system-9 (ADS-9) software in Iran and Shahid Beheshti Universities teaching hospitals, 2002. Hakim Res J. 2003; 6(3):45-53.

[28] Pankratz M, Hallfors D, Cho H. Measuring perceptions of innovation adoption: The diffusion of a federal drug prevention policy. Health Educ Res. 2002; 17(3):315-26. [DOI:10.1093/ her/17.3.315] [PMID]

[29] McGaw J, Conner DA, Delate TM, Chester EA, Barnes CA. A multidisciplinary approach to transition care: A patient safety innovation study. Perm J. 2007; 11(4):4-9. [DOI:10.7812/ TPP/07-012] [PMID] [PMCID]

[30] Aligol M, Mohammadbeigi A. [Assessment of private sector physicians' willingness to participate in family physician program using the diffusion of innovation model (Persian)] Qom Univ Med Sci J. 2014; 8(1):27-34. http://journal.muq. ac.ir/article-1-167-en.html 
This Page Intentionally Left Blank 